\title{
First record of coralline lethal orange disease (CLOD) in the Indian Ocean
}
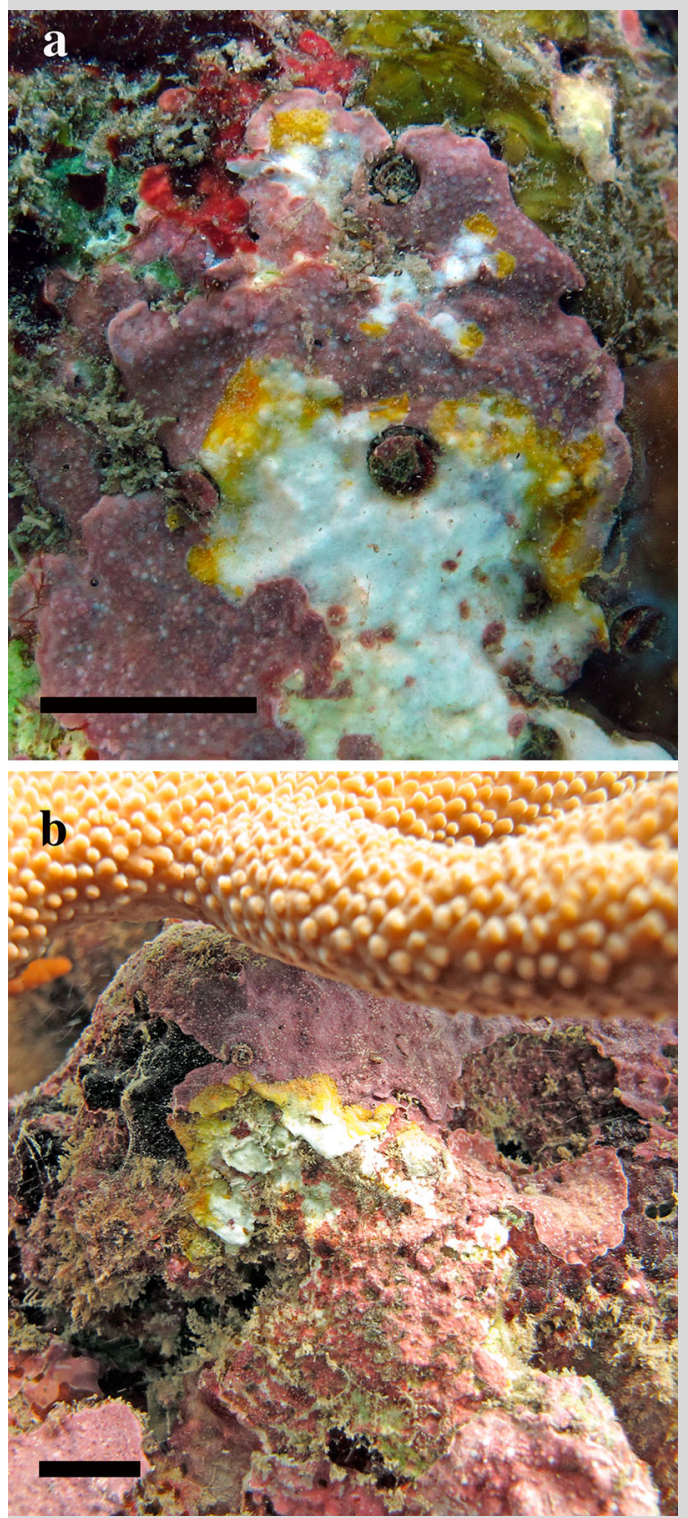

Fig. 1 Multiple lesions of coralline lethal orange disease on a reef in the Gulf of Mannar, India, a close-up view of lesions and b portrait view of a 2 nd lesion. Scale bar $1 \mathrm{~cm}$
Disease outbreaks in marine organisms are increasing worldwide and contributing to the deterioration of global coral reefs. Crustose coralline algae (CCA) play a key role in coral reef ecosystems providing settlement sites for coral larvae and producing carbonate which helps maintain reef structures (McCoy and Kamenos 2015). Disease in CCA can cause significant, direct mortality and can have important downstream effects such as reducing survivorship of coral larvae (Quere and Nugues 2015). Despite their potential importance, little is known about the distribution, ecology, or pathogenesis of CCA diseases (VargasAngel 2010). Here we report the first cases of coralline lethal orange disease (CLOD) on reefs within the Indian Ocean (Fig. 1a, b). Three cases of CLOD were found on Villanguchalli patch reef (N08 $55.179^{\prime}$, E078 $\left.15.651^{\prime}\right)$ in the Gulf of Mannar, southeastern India. All three cases were clustered together within approximately $60 \mathrm{~cm}$ of each other. CLOD has been reported throughout the Pacific Ocean (VargasAngel 2010), but this report extends the geographic range of this disease into the Indian Ocean. Gulf of Mannar is one of the four major coral reef areas in India and has protective status as a marine national park. Systematic research on diseases of these reefs is planned and has the potential to unveil further new findings to the Indian Ocean region.

Acknowledgments The Ministry of Environment, Forests and Climate Change, and the Science and Engineering Research Board, Department of Science and Technology, Government of India provided funding. Thanks also to Dr. V.K. Melkani, Chief Wildlife Warden, Government of Tamil Nadu, India, and Mr. Deepak S. Bilgi, Wildlife Warden, Gulf of Mannar Marine National Park, for research permissions.

\section{References}

McCoy SJ, Kamenos NA (2015) Coralline algae (Rhodophyta) in a changing world: integrating ecological, physiological, and geochemical responses to global change. J Phycol 51:6-24

Quere G, Nugues MM (2015) Coralline algae disease reduces survival and settlement success of coral planulae in laboratory experiments. Coral Reefs [doi: 10.1007/ s00338-015-1292-0]

Vargas-Angel B (2010) Crustose coralline algal diseases in the US-affiliated Pacific Islands. Coral Reefs 29:943-956

\section{G. S. Aeby ( $\bowtie)$}

Hawaii Institute of Marine Biology, University of Hawaii, Honolulu, HI, USA

e-mail: greta@hawaii.edu

K. D. Raj · G. Mathews · M. S. Bharath · J. K. P. Edward

Suganthi Devadason Marine Research Institute, Tuticorin, Tamilnadu, India

Received: 8 April 2015/Accepted: 26 June 2015/Published online: 3 July 2015

Coral Reefs (2015) 34:1177

(C) Springer-Verlag Berlin Heidelberg 2015

DOI $10.1007 / \mathrm{s} 00338-015-1323-\mathrm{x}$ 